\title{
African American Students' Experiences of the School-to-Prison Pipeline: A Phenomenological Study
}

\author{
Timmesha A. Butler ${ }^{1 *}$
}

${ }^{1}$ Ramapo College of New Jersey, UNITED STATES

*Corresponding Author: tbutler4@ramapo.edu

Citation: Butler, T. A. (2022). African American Students' Experiences of the School-to-Prison Pipeline: A Phenomenological Study, Journal of Cultural Analysis and Social Change, 7(1), 04. https://doi.org/10.20897/jcasc/11529

Published: July 31, 2022

\begin{abstract}
Objective: The school-to-prison pipeline (SPP) is a phenomenon that describes pushing students out of public schools into the juvenile justice system. Research notes that Black students with disabilities are disproportionately affected by the school-to-prison pipeline. This article details a phenomenological qualitative research study that explored the lived experiences of Black students with disabilities, who, by virtue of experiencing school discipline and juvenile detainment, have become involved in the school-toprison pipeline.

Method: Using a Critical Disability Theoretical framework, the researchers sought to use the voices of students most affected to develop an understanding of the SPP. A sample of 10 African American Students was selected from alternative schools to describe their experiences with school discipline and the juvenile justice system.

Results: Findings in the research study noted three critical aspects of the students' journeys: the relationships they developed with caring educators, distrust in the criminal justice system, and a developed sense of false consciousness.

Conclusion: This article seeks to use students' experiences to provide insights into how school professionals can address the complex nature of this phenomenon.
\end{abstract}

Keywords: students with disabilities, African American, Black, school-to-prison pipeline, juvenile justice, phenomenology

\section{INTRODUCTION}

Students labeled with behavior and emotional disturbance disabilities are often labeled and disproportionately targeted for severe school disciplines such as suspension, expulsion, and school-based arrest (Fenning and Rose, 2007; Marchbanks and Blake, 2018). Researchers have conceptualized school discipline practices streamlining students into the juvenile justice system as the School-to-Prison Pipeline (SPP) phenomenon. Students that are mostly affected by this phenomenon are Black students with disabilities.

Students who experience the SPP and are involved in the juvenile justice system become 39 percent less likely to graduate and 41 percent more likely to enter into adult prison by the time they reach the age of 25, with Black youth more likely to recidivate than Caucasian youth (Aizer and Doyle, 2013; Office of Juvenile Justice Delinquency Prevention (OJJDP), 2017). Additionally, students with disabilities who have experienced juvenile justice involvement have higher rates of mental health concerns, including suicidal ideation (Scott et al., 2015). While there is significant research to describe the effects and risk of juvenile justice involvement for students with 
disabilities (Aizer and Doyle, 2013; Hockenberry et al., 2015; Losen, 2018; Sickmund and Sladky, 2015), there is limited research that highlights students' perceptions of their experiences. Therefore, the purpose of this phenomenological research study is to examine the experiences of Black students with disabilities who have been involved in the juvenile justice system in the United States.

This article provides a review of the theoretical, empirical, and scholarly literature related to Black students with disabilities, their educational experiences, and juvenile justice involvement. The literature review also describes the use of Critical Disability Theory as the theoretical foundation of the research study. Following the literature review, the article explains the research study's methods, data analysis process, and findings. Additionally, the article concludes with a discussion of the findings and implications for school social work practices

\section{LITERATURE REVIEW}

\section{History of the School-to-Prison Pipeline}

During the late 1980s, there was an increase in school-related shootings and juvenile arrests for violent crimes, resulting in the perception that adolescents were becoming viciously dangerous (Puzzanchera and Hockenberry, 2013). Juveniles "wilding," being violent and unmanageable in the streets and on school campuses, was a perceived threat to the safety of society. Federal and state governments began to address this issue by implementing strict policies like the Gun-Free Schools Act (GFSA) (GFSA, 1990) and zero-tolerance policies to promote behavior changes (Vlaev and Dolan, 2015).

Implementation of GFSA encouraged several school districts to adopt zero-tolerance policies as a model to address students who brought guns to school; however, it evolved to target a broad spectrum of behaviors. It created a framework for schools to implement severe punishments and disciplinary actions without any cognizance of behaviors or the settings in which the behaviors occur. Discipline policies like GFSA and zero-tolerance policies began to establish academic environments that mimicked prisons, with an increase in police presence and the use of metal detectors in underprivileged low-income schools.

With the increase of school-based police officers (SROs), discipline concerns traditionally handled by school staff are assigned to SROs that use more punitive or physical methods to de-escalate behaviors (Hirschfield, 2008). The officers' presence increases the criminalization of school-based behaviors for minority students and students with disabilities, increasing the rates of suspension, expulsion, and school-based arrest (Mallett, 2016)

\section{Racial and Disability Disproportionalities in School Discipline}

Researchers have found that suspensions and expulsions are typically ineffective in behavior modification, and they are often detrimental to academic achievement and well-being (Denby and Curtis, 2013; Gibson et al., 2014; Raffaele-Mendez and Knoff, 2003). Despite the research, suspension and expulsion continue to be the immediate option to reprimand unwanted behaviors, and students of color with disabilities are disproportionally targeted. In US public schools, students with disabilities represent $13.2 \%$ of student enrollment but $24.5 \%$ of students that receive one or more out of school suspensions and $38.1 \%$ of students expelled (US Department of Education Office of Civil Rights, 2021).

Literature notes that suspension and expulsion rates are disproportionate due to the pathologizing of behaviors in public schools (Denby and Curtis, 2013), implicit bias among school staff (Aleguire et al., 2016), lack of cultural awareness, inexperienced teachers (Losen et al., 2014), or a combination of all four factors (DeMatthews, 2016). Research indicates that Black youth are often penalized for school-related offenses that are subjective rather than objective. In a study conducted by Annamma et al. (2019), researchers found that Black girls, in particular, were more likely referred to the office for perceptions of negative behavior like defiant attitudes, disobedience, and assault; rather than objective offenses like possession of alcohol and drugs.

Disproportionality in suspensions and expulsions is significantly elevated for students who identify as Black and a person with a disability. In 2018 for every 100 students with special needs, White students missed 43 days of instruction due to suspension and expulsion compared to Black students who lost 121 days (Losen, 2018). Notably, students classified with emotional disturbance disorders are the most at-risk group for suspension and expulsion (Losen et al., 2014; Miller and Meyers, 2015). Black students are the most at-risk group to be classified as students living with emotional disturbance (Losen et al., 2014; Miller and Meyers, 2015). Additionally, the US Department of Education Office of Civil Rights Data Collection (2021) confirms that rates of school-based arrest and lawenforcement referrals are disproportionate for students of color with disabilities compared to their non-disabled and white peers. Expressly, Black students with disabilities represent $2.3 \%$ of student enrollment, but $8.4 \%$ of students referred to law enforcement and $9.1 \%$ of students arrested (US Department of Education Office of Civil Rights, 2021). 


\section{Racial and Disability Disproportionalities in the Juvenile Justice System}

Disproportionalities in discipline extends beyond the classroom. While Black youth are more likely to be arrested and detained in general, the intersectionality of race and disability increases the risk for Black youth with disabilities. Among the 40,000 youth incarcerated, 44 percent are Black, despite Black students only representing 16 percent of youth nationwide (Rovner, 2016). Eighty-five percent of all juveniles incarcerated have a learning or emotional disturbance disorder, and over half of the youth identify as Black (NCD, 2015).

The racial disproportionality in arrest rates is not indicative of a difference in crime and offenses. Black and White youth typically commit the same disciplinary infractions. White and Black youth are likely to get into fights, skip school, and sell and use substances at similar rates (Rovner, 2016). However, Black youth are often viewed as more violent, promiscuous, disrespectful, older, and less innocent than their White peers resulting in the disproportionalities that exist in school discipline. Black youth are overrepresented for corporal punishment, referral to law enforcement, school-related arrest, and expulsion (Hines-Datiri and Carter Andrews, 2020; Rovner, 2016; The Sentencing Project, 2017; US Department of Education Office of Civil Rights, 2021). Black youth with disabilities are more likely to have their behaviors contributed to delinquency rather than their disabilities, resulting in stricter and harsh consequences (Ramey, 2015). The effects of harsher punishments such as suspensions, expulsion, and arrest, can range from academic deficits to mental health concerns.

\section{Effects of juvenile justice involvement}

When students with disabilities are arrested and detained, they lose access to educational and therapeutic service hours, such as tutoring, therapy, and counseling. The Individual Disabilities Educational Act (IDEA) mandates that students receive academic instruction while detained; however, research suggests that educators employed in juvenile facilities are not adequately equipped to offer specialized education (Macomber et al., 2010; SheldonSherman, 2013). Juvenile justice involvement reduces the chance of school completion, and students become 49 percent less likely to graduate and 41 percent more likely to enter adult prison by the time they reach 25 (Azier and Doyle, 2013).

Black youth with disabilities are more likely to recidivate in 2.75 years compared to their peers without disabilities, who are more likely to recidivate in 7 years following their release (Loughran et al., 2009; OJJDP, 2017; Zhang et al., 2011). The ongoing cycle of incarceration stemming from juvenile arrest is the catalyst to students solidifying their place in the school-to-prison pipeline.

\section{THEORETICAL FRAMEWORK}

The theoretical foundation of this study is drawn from Critical Disability Theory (CDT), a modified version of critical theory. Critical theory promotes the evolution of power and equality in human society and gives all people the freedom to confront and ultimately transcend societal oppression. It stresses the importance of understanding oppression to advocate for true social justice. CDT uses the major principles of critical theory with a specific focus on challenging policies and structures that discriminate against individuals with physical and mental disabilities (McGowan, 2014). Applying CDT to this research study involves a consideration of false consciousness, the social and medical models of disabilities, honoring the voices of individuals living with disabilities, and multidimensionality among individuals with disabilities.

False consciousness refers to the process of marginalized groups internalizing oppression. In CDT, false consciousness is represented by internalized ableism, where individuals living with disabilities blame themselves for the incompetence of social institutions (Campbell 2008, as cited in Hall, 2019). This is partially due to the social model of disability, as the dominant paradigm for understanding disabilities is a medical model. The medical model perceives disabilities as disadvantages that should be fixed and cured to increase assimilation into the ableist society (Hogan, 2019; Hoskings, 2008). CDT encourages social institutions to view a disability as a social construct categorized by the interrelationship between response to impairments and the social environment (Hosking, 2008). It identifies the social environment's failure to meet the needs of people as the antecedent of the disadvantages experienced by individuals with disabilities. Hosking (2008) notes that "it is only by listening to and valuing the perspectives of those who are living disabled lives that the able-bodied can begin to understand [the needs of those living with disabilities]" (p.13). Individuals with disabilities have the power of autonomy and self-determination (Hoskings, 2008; Procknow et al., 2017). CDT indicates that to effectively address the needs of individuals living with disabilities, institutions must be safe spaces for them to openly voice their concerns and advocate for themselves.

Lastly, CDT acknowledges the multidimensionality that exists among individuals living with disabilities. Multidimensionality combines intersectionality (experience of two or more separate oppressions) and hybridintersectionality, the intersection of privilege and subordination (Hosking, 2008). Inasmuch, this element of CDT 
suggests that institutions should be conscious of the range of experiences among individuals with disabilities. Multidimensionality is the essence of the disproportionalities within school discipline and juvenile justice involvement. Some similarities exist among Black students with disabilities and their White peers and Black male students living with disabilities and their female peers; however, their experiences have distinct differences (Annamma et al., 2019; Losen et al., 2014). Multidimensionality develops a platform to understand how individual characteristics paired with unique experiences should be the basis of intervention plans and policies when addressing disparities within disability studies.

The researcher used these core concepts as a framework in developing the full research agenda for this study. Consistent with the "voices" element of CDT, the research study uses a qualitative method to establish an opportunity for participants to use their voices to shed light on their experiences. The premise is to enhance the research on this phenomenon and develop an in-depth understanding of how students with disabilities experience the SPP. Core elements of CDT were also used as a framework when developing the data collection tool and analyzing the students' responses.

\section{METHODOLOGY}

Limited knowledge exists about the SPP's complex nature and the extent to which an individual experiences this phenomenon. This research study sought to explore two aspects of this complex phenomenon (school discipline \& juvenile justice involvement) through the voices of those most affected. This qualitative phenomenological study aimed to use the participants' voices to gain insight into their experiences and inform the development of policies and practices that effectively address the needs of a vulnerable population

\section{Research Design}

This research study used a social constructivist phenomenological approach to examine the lived experiences of Black students with disabilities. Phenomenology was the best fit for this study as it views subjective experiences and interpretations as central to a critical understanding of the world (Moustakas, 2018). Social constructivism suggests that multiple realities exist, and the knowledge of those realities is only understood through daily interactions and communications (Andrews, 2012). Accessing the participants' experiences and perceptions provided a profound basis for understanding the SPP and how it influences the lives of its victims. Applying a social constructivist paradigm was aligned with CDT and granted the space for participants to use their voices and perspectives to create a foundation for future advocacy in the field of social work, education, and criminal justice.

The study aimed to answer the following research question: What are the lived experiences of school discipline among African American students with disabilities who bave been involved in the JJS?

\section{Research Site and Participant Selection}

Three alternative high schools were purposely selected to complete this study based on geographical location and student enrollment demographics. In Washington, DC and Maryland, alternative schools are primary and secondary schools that offer non-traditional educational experiences for students who struggle to succeed in traditional educational settings. In both high schools in Washington DC, Black students represented over 95\% of the student population (DCPS, n.d.). The schools provided several educational programs for students who have been suspended or expelled from comprehensive school settings. The alternative school in Maryland offered smaller classroom sizes for students between the ages of 11-21 with emotional and behavioral disabilities.

The researcher gained access to study participants through purposive sampling. The study used a homogenous sampling method to identify students who met the following criteria: African American, between the ages of 1825, with a diagnosed learning and or behavior disability, and past or present juvenile justice involvement. Participants were recruited with flyers, distributed by designated employees that instructed them to contact the researcher if they met inclusion criteria and were willing to participate. Thirteen students contacted the researcher; however, only 10 of the students met the study's full criteria. Students ranged between the ages of 18-20; there were eight males and two females. All the students were required to have an individualized education plan (IEP). IEPs are written plans that outline the specialized educational and related services that schools are required to implement to increase academic success among students living with disabilities. To obtain an IEP, a student must qualify under one of the thirteen disability statuses outlined in the Individuals with Disabilities Education Act of 2005. While the students were not asked to disclose a description of their disability, five of them mentioned a diagnosis of ADD/ADHD. Two of the students indicated that they struggled with staying focused in class. Eight of the 10 students reported being arrested between 1-5 times, and two of the students reported being arrested more than 15 times (see Table 1). As students in the study were over the age of 18, parental consent was not required. Pseudonyms were used to protect the identity of the participants. Participants are identified as Brenton, Winston, Samantha, Taylor, Matthew, Marcus, Derrick, Jason, Jose, and Darron. 
Table 1. Demographics of participants

\begin{tabular}{|c|c|}
\hline Descriptor & $\mathbf{N}(\%)$ \\
\hline \multicolumn{2}{|l|}{ Gender } \\
\hline Male & $8(80)$ \\
\hline Female & $2(20)$ \\
\hline \multicolumn{2}{|l|}{ Age } \\
\hline 18 & $3(30)$ \\
\hline 19 & $4(40)$ \\
\hline 20 & $3(30)$ \\
\hline \multicolumn{2}{|l|}{ Grade } \\
\hline $10^{\text {th }}$ & $1(10)$ \\
\hline $11^{\text {th }}$ & $1(10)$ \\
\hline $12^{\text {th }}$ & $8(80)$ \\
\hline \multicolumn{2}{|l|}{ Times Arrested } \\
\hline $1-5$ & $8(80)$ \\
\hline $15-20$ & $1(10)$ \\
\hline Unsure & $1(10)$ \\
\hline
\end{tabular}

Note: $\mathrm{N}=10$

\section{Data Collection and Analysis}

Consistent with the seven elements of CDT, a phenomenological approach, and social constructivism, the researcher conducted in-depth individual interviews composed of 16 open-ended questions. One interview was conducted per student, and they each lasted approximately 60 minutes. The researcher developed an open-ended semi-structured interview guide using relevant literature and CDT, informed by the researcher's professional and personal experiences. Participants were asked questions like:

Tell me about your experience becoming aware of your disability, who told you, how did it make you feel? What is your understanding of your IEP, what does it mean? Tell me about the supports you receive that assist you with your struggles? How would you describe your experiences building relationships with your teachers and other staff? Have you ever felt that teachers or staff did not like you or viewed you negatively? If yes, tell me an experience you had with a teacher that made you feel this way? Was there ever a time you felt the discipline you received was unfair? If so, describe that experience? I'd like you to think of a time that you were disciplined for your behavior at school. Describe your experience and how it made you feel. Do you feel like the discipline or consequences you received were equal to your behaviors? How did your experience of the juvenile justice interaction affect your overall well-being? If you could suggest anything you want to staff, teachers, and others in regard to students with disabilities, what would you suggest?

\section{Data analysis}

Data collected from the interviews were transcribed and analyzed using a modified Van Kamm approach, developed by Clark Moustakas (Creswell, 2014). This approach consisted of the following five steps: epoche, horizontalization, textural description, structural description, and the combination of textural and structural description.

Epoche referred to the process of bracketing where the researcher recognized and set aside prior knowledge, experience, and assumptions about the phenomenon to analyze data with an open mind (Creswell, 2014; Yuksel and Yildirim, 2015). Horizontalization consisted of reviewing the data and identifying significant words and statements from the students' interviews, and grouping them into themes. There were a total of 6 themes that evolved from the data, which described the students' general perceptions of their experiences. The next step, structural description, required the researcher to create a narrative textural description using verbatim examples derived from the interviews to highlight the settings in which the students experienced the phenomenon (Creswell, 2014; Yuksel and Yildirim, 2015). In phenomenology, the goal is to uncover the essence of the overall experience rather than comparing and contrasting. To accomplish this, the final stage included combining the textural and structural description to describe the essence of the students' overall lived experiences of the SPP

\section{Trust Worthiness and Rigor}

Lincoln and Guba identified four values in the research process: truth value, applicability, consistency, and neutrality (Pandey and Patnaik, 2014). Truth value in qualitative studies can be subjective; therefore, reflexivity and peer-debriefing were the most effective way to enhance truth value. To maintain applicability, rich, thick descriptions of the participants and settings were included in the study to help research consumers determine if the study can be transferred through shared characteristics (Creswell, 2014). An audit and log of the detailed 
Table 2. Essential themes and evidence in student's statements

\begin{tabular}{|c|c|}
\hline Essential themes & Evidence in student's satements \\
\hline \multirow{4}{*}{ "I didn't know what my IEP was." } & "They didn't really describe nothing." \\
\hline & "I don't know what my disability is." \\
\hline & "I'm aware that I have an IEP, but I don't know what it's for." \\
\hline & "Like I'm retarded or something." \\
\hline \multirow{4}{*}{ "I appreciated teachers who cared." } & "If a teacher is supporting you, it makes you want to come to school." \\
\hline & "She knew I had problems, but she never used it against me." \\
\hline & "My IEP will be like, 'No, I can sit down and help you. I can go over your work with you." \\
\hline & $\begin{array}{l}\text { "You don't have to call, you ain't got to deal with no type of student, but he chose to deal } \\
\text { with me." }\end{array}$ \\
\hline \multirow{4}{*}{ "Every discipline I got I deserved." } & "All of the discipline I got I deserved because I did it to myself." \\
\hline & "The people at the school kept giving me chances...I wanted to be wild." \\
\hline & "Till this day I'm happy I got locked up." \\
\hline & "It was necessary because I was wrong." \\
\hline \multirow{4}{*}{ "I don't respect the police." } & "That just made me not like the police." \\
\hline & "I was the kid that never got in trouble until, you know, the police officers blamed me." \\
\hline & $\begin{array}{l}\text { "I'm not going to say I'm scared of the police, but when they start to ask me questions, I } \\
\text { instantly get nervous." }\end{array}$ \\
\hline & "It made me look at the police like I can’t even trust these people." \\
\hline \multirow{4}{*}{ "I could have been graduated." } & "I could have been graduated, but I got in trouble with the law." \\
\hline & "I'm 20 and about to graduate. I should have graduated in 2018." \\
\hline & "I stayed back three times, and I'm still in school trying to get out." \\
\hline & "As you see I'm still in the $12^{\text {th }}$ grade at 20, when my class, my class was 2016 , It's 2019." \\
\hline \multirow{4}{*}{ "I wish someone would have seen me." } & "I'm not stupid. I'm intelligent as hell." \\
\hline & "I wish somebody would have seen I was just a lost kid that needed help." \\
\hline & "Be mindful...you don't know what is causing these issues at home." \\
\hline & "Listen to both sides of the stories before choosing one person side." \\
\hline
\end{tabular}

process and peer examination were used to address consistency. Lastly, a review of the history, progression and decision-making steps helped maintain neutrality.

\section{Ethical Considerations}

Several methods were used to prevent risk to the study participants. Threats of emotional distress, emotional harm, and a threat to justice are the ethical concerns specific to this form of qualitative research (Hewitt, 2007; Townsend et al., 2010). As a social worker engaging in qualitative research, it was essential to use reflexivity throughout the study to prevent the researcher from intervening in possible incidents of emotional distress. To prevent this from occurring, at the beginning of the interviews, the researcher provided the participants with a distress protocol that included the contact information for the Washington, DC access helpline for counseling services.

In compliance with social work research ethics, the researcher submitted a research proposal to the District of Columbia Public Schools, which was reviewed and approved by DCPS (n. d.) research department attorneys. Additionally, in compliance with the guiding principles of ethical research, the researcher obtained IRB approval for the study from the Committee for the Protection of Human Subjects at The Catholic University of America.

Lastly, before the findings of this study are discussed, it is important to acknowledge the author's standpoint as an African American woman and educator. While the author has not experienced the school-to-prison pipeline as a student, the author has observed the disproportionalities in school discipline and the juvenile justice system as it pertains to Black students living with disabilities. The author acknowledges that their positionality could have influenced this research project to some degree: access to participants and interpretations of the data. In attempts to avoid misinterpretation, the author made efforts to bracket existing biases and assumptions.

\section{FINDINGS}

Six essential themes evolved from the students' responses, and collectively, the six themes informed the essence of the students' overall experience. The six themes were identified as "I didn't know what my IEP was," "I appreciated teachers who cared," "every discipline I got I deserved," "I don't respect the police," "I could have been graduated," and "I wish someone would have seen me." Table 2 displays a list of the themes and the evidence of those themes in students' statements. 


\section{“I Didn't Know What My IEP Was"}

"I was getting in trouble in school, I was getting into fights or altercations, or just doing anything in school not going to class. That is when they was like 'Oh, he got an IEP'... [I thought it meant] that I was retarded." (Jason)

The above quote is a representation of the theme, "I didn't know what my IEP was." Many of the students expressed that their initial understanding of their IEPs was minimal, leaving them confused and subjected to negative self-doubt. Two of the students were currently unsure of their disability classification or what it meant to have an IEP. The other eight students who had a general understanding of their disability status described gaining clarity on their own as they matured and gained experience in the educational settings. In Jason's description of his introduction to the IEP process, he immediately viewed it as negative, labeling himself "retarded". One student, Matthew, described his introduction to his IEP and the IEP processes as "unfavorable". Matthew shared similar thoughts to Jason about his initial perception of his IEP. In Matthew's words,

"I [thought] like, I was retarded or something. It made me feel not right like I did not want to be around people".

Jason's and Matthew's initial perception of their IEPs resulted in isolation from their peers, and it eliminated their abilities to apprehend the nature of their disabilities and how it affects their behaviors.

Without a proper understanding, they accepted negative stereotypes constructed by society as a foundation for understanding their disabilities. As their knowledge increased, they overcame the stigmas and viewed their IEPs like a process set in place to increase their chances of academic success.

\section{"I Appreciated Teachers Who Cared"}

"I'm homeless when I leave from this school. Every day he asks me, You good? You hungry? You need something to eat? Where you staying at? Call me. Like he gives me a time - 6 o'clock, 7 o'clock, when he off. That's just extra right there. When you off the clock, you don't have to call, you ain't got to deal with no type of student. But he chose to deal with me." (Derrick)

Derrick's statement exemplifies how the students valued educators who genuinely cared about their well-being despite their challenges. During the interviews, the students noted that in their earlier years of receiving IEP services, teachers in comprehensive schools often labeled them as "bad", "bullies", "crazy", and "disrespectful". Marcus indicated that his teachers in the comprehensive schools eventually gave up on him. Once the students transitioned into the alternative school setting, they encountered teachers who cared. In this setting, teachers used positive and encouraging language, increasing the students" opportunity to "stand on the good," as noted by Brenton. The relationships with helping educators were transformative in creating a sense of resiliency and determination.

For some of the students, the teachers' positive support filled the gaps of positive relationships they lacked at home. For students like Derrick and Winston, educators mirrored their father and grandmother because they showed interest in their academic and overall well-being. Winston described a relationship with a caring educator who reminded him of his grandmother. Winston expressed,

"yeah she just tells me I can do it...she will have little talks with me... I look at her like a grandmother, cause my grandmother died. [] respect her with the upmost respect."

\section{"Every Discipline I Got I Deserved"}

"All of the disciplines I got, I deserved because I did it myself, so I can't sit here and blame nobody else for something I did. Every discipline that I've got, I've been locked up every time". (Taylor)

Nine of the ten students expressed that they deserved the discipline or consequence they received. They viewed this as taking responsibility for their actions. Taylor, who described being arrested every time she got in trouble at school, labeled her actions as wild, contagious, and problematic. Taylor was arrested so often for fighting; eventually, she was charged as an adult. Jason and Derrick both described being physically managed, and they believed that the educators who physically restrained them "were doing their jobs". Samantha was not a victim of physical management; however, she believed that the disciplines she received were "dumb" but mimicked "real world" natural consequences.

The students internalized the harsh disciplines, self-blamed, and perceived their experiences as evidence that they needed to adjust their behaviors. While the students self-blamed and attempted to make sense of the discipline 
they received, they developed a lack of respect for law enforcement officers that often intervened in their educational settings. The next theme, "I don't respect the police," reflects their experience.

\section{"I Don't Respect the Police”}

"It made me [feel like] you can't trust nobody with no badge. Cause they got that badge for a reason. Obviously, that badge is compensating for something, and people who got to have something to compensate for something, they scared. And scared people make the worst decisions." (Brenton)

Brenton's statement reflects how his experiences with police officers were consistently negative. Like Brenton, many participants described fear and dissatisfaction in their interactions with law enforcement officers. Their perspectives were developed based on the treatments they received in school, in their communities, and while incarcerated. Winston and Matthew were two other students who were adamant about their distrust of the police. Winston had a long-standing history with police officers noting, "people have been calling the police on me all my life.. and every time I seen the police, it was disrespect." Matthew became so frustrated with the adverse interactions that his tolerance for police officers decreased, leading him to approach an SRO "man to man" in a physical fight.

The dissatisfaction and distrust for law enforcement officers were evident in the students' voices, and they made it clear that law enforcement officers made them feel unsafe and unheard. The next theme describes the students' experience being derailed from their academic journeys due to their involvement with law enforcement officers and the juvenile justice system.

\section{"I Could Have Been Graduated"}

"I was doing all my work, and they didn't grade me properly...juvenile detention system didn't send my grades...they lost half the work I did." (Taylor)

"Everything was getting lost, like everything, a lot of my paper works, and stuff was getting lost. So it was like damn." (Jason)

As a result of being incarcerated, students could not access adequate education, and assignments completed during their incarceration got lost in transition. Taylor's and Jason's statements are a testament to the way students experienced education while incarcerated. None of the students were in their appropriate grades, missing their deadlines to graduate from high school. Nine of the ten students described their involvement in the JJS as the reason for their educational setbacks.

Darron stated that he received worksheets while incarcerated; however, they were below grade level. In his words, "it wasn't my grade-level work, so like, when I got to school...I didn't know the work because I was doing [lower grade] work." Similarly, Derrick described, "I was in the 12th grade, and they gave me $9^{\text {th }}$ grade, 8th grade work, and expect me to want to graduate from there, no." Matthew and Winston attributed their setback to being isolated or in the hole 24/7 while incarcerated and not receiving any education during those times.

Nine of the students had negative experiences. Jose was the only student who referred to the educational services as "up to par". Students were aware of the traditional process of completing assignments and turning them in for a grade; however, the others all reported that the process was insufficient. This process left students extremely disappointed, internalizing the absence of their academic accomplishments as a result of their behaviors rather than a flaw in the system.

\section{"I Wish Someone Would Have Just Seen Me"}

"I mean, I'm not no little guy, I'm 6'3. At the time I was like 6 foot in the 7th grade, so I was towering over everybody. Like I was the only person who was my size. So I feel like when they looked at me, they saw, for real, for real was a grown man. They was looking at me like I was trying to hurt somebody." (Brenton)

The final essential theme represents the students' desire to be viewed as positive individuals who should be treated fairly at all times. Within this theme, the participants expressed how they were viewed unfavorably due to their physical characteristics (race and physique) or behavior struggles in the academic setting. Derrick and Samantha both had strained relationships with their parents, and they both believed that the labels of being bad students prevented educators from engaging with them. Derrick notes that he was "lost" in school partly because he grew up in the "system" and didn't have a family to support him. He described his behaviors at the time as "attention-seeking," and he wished in the early days of his education that "somebody would have seen" that he "needed help." Similarly, Samantha believed her association with a self-contained classroom was overemphasized in her reputation. She was aware of the negative stigma associated with self-contained classrooms; however, she wanted her educators to see her as a student who wanted to learn despite the label she received. 
Brenton, Taylor, and Winston also struggled to be seen; however, their experiences were solely related to their physical attributes. Taylor and Winston revealed that their race might have contributed to school staff viewing them as aggressors. They believed that they were unfairly treated and unheard because they were Black. For Brenton, it was his height and size. He reflected on his experience of wanting to be seen as a child and not as a violent adult.

All the students' complex backgrounds and their early experiences of being diagnosed with learning and or behavior disorders increased their sense of vulnerability. In the traditional school settings, they were punished harshly, consistently flagged for discipline, and experienced discrimination in various ways. Adverse life experiences paired with their interactions at school left them feeling unseen, unfulfilled, and unequal.

\section{DISCUSSION}

\section{Essence of the Overall Experience}

Each student offered a unique perspective of their experiences of the phenomenon. However, in all their experiences, the participants described a journey that shifted their perspectives. Their initial discernment of the SPP was negative. However, as they became accustomed to their environments and gained access to teachers who showed interest and care in their well-being, they reported a shift to a more positive perspective of their experiences. Students had no regrets of their experiences, and many of them used phrases like "god's plan," "everything happens for a reason," "I am happy that it happened," "I see growth in myself," and "it helped me learn how to conduct myself."

The participants believed that they were responsible for their behaviors, and this was evidence of false consciousness. As they experienced discipline, school mobility, and detainment, they began to view the process as expected and required. The students' interpretation of their experiences is vastly problematic. Despite a general understanding of their disabilities, the students were still unaware of how their disability status was defined as the inability to control and manage their behaviors. Therefore, they were not to blame for their trajectory in the SPP.

\section{Connections to Existing Literature}

This study's findings are consistent with the research on the school-to-prison pipeline, the disproportionalities that exist for Black students with disabilities, and the detrimental effects of the SPP (Macomber et al., 2010; NCLD, 2015; Snyder and Sickmund, 2006). The findings are also consistent with the concepts outlined in CDT. Students described feeling unseen, voiceless, and disregarded as a result of their race and disability status. Without an understanding of their IEPs and disabilities status, they were unable to advocate for themselves in crucial times. The students experienced false consciousness as the educational institutions traditionally upheld the medical model of disabilities, aiming to "fix", rather than accommodate students. According to Charlton (as cited in Rocco, 2005), a sense of false consciousness is often experienced by individuals with disabilities when unaware of the social conditions, institutions, and oppressive forces working against them. While the participants were exposed to the adverse effects of the SPP, their understanding of their roles in the phenomenon was problematic. The participants believed they could have been "fixed" to prevent themselves from living traumatic experiences. Their perceptions forced them to adapt to problematic expectations of themselves and others. Students self-blaming and taking responsibility in this study reflects society's views that a disability is a medical condition that can be "fixed". In the alternative schools where teachers used empathy, compassion, and care to engage students, the students felt a sense of resilience despite their negative experiences in comprehensive school settings and juvenile detention centers.

While the study reveals that the SPP's adverse effects (low educational attainment, recidivism, and mental health concerns) were present amongst the students, the findings also reveal an alternative reality. This acknowledgment of an alternative reality is consistent with phenomenology and social constructivism (Andrews, 2012). The study participants were amid a "second chance" at graduating high school; therefore, the meanings they assigned to their experiences were rooted in a new positive perspective. The participants in this study found a sense of hope undeterred by their journeys in the SPP. The students developed meanings in relation to the SPP phenomenon based on their ability to connect with teachers who showed interest in their overall well-being.

\section{LIMITATIONS}

The study has several limitations. First, the study sample was limited by the study design and research question, targeting students who fit within a specific category and possibly excluding students who wanted to participate. The study consisted of 80 percent males and 20 percent females. While qualitative research is not generalizable, the disproportionate rates in gender are not representative of the entire population. It is worth noting that Black girls are the fastest-growing demographic among students experiencing the SPP (Morris, 2016; Hill, 2018). Black 
girls have a higher percentage of punishments than other female students, at rates that exceed the majority of male students (Hines-Datiri and Andrews, 2020). Lastly, the study occurred in alternative schools. The location prevented the researcher from accessing participants who were still facing harsh realities in traditional school settings, students who remained incarcerated, and students who may have dropped out. The perceptions from this small and specific sample size can give a misconception that the SPP is not severe and traumatic. Future social work research may examine differences between the students in this study and other students who have not found a new sense of hope undeterred by their journeys.

\section{CONCLUSIONS}

This study gave a voice to a population that is traditionally silenced through institutional and systemic oppression. Using the students' voices to develop an in-depth understanding of their experiences, social workers, educators, and justice officials can change the lives of students most vulnerable in the educational system. Findings in this study suggest that positive outcomes can exist despite JJS involvement. However, for students with disabilities resiliency should not come as a consequence of trauma. Participants' responses showed the importance of minimizing harsh discipline, law enforcement involvement, and educational setbacks. Academic success for the students in this study was credited to the teachers and school staff who increased social support, adequate educational resources, and student buy-in. Educators who were connected to the students in this study were reactive. The reactive measures reflect the social model of disabilities, where institutions focus on increasing social support and adequate resources to address the needs of individuals living with disabilities. Educational institutions can use the findings from this study as a guideline to develop proactive methods to provide students with the educational settings necessary to bypass journeys through the SPP. A future research study would seek to explore the effectiveness of using a social model of disabilities framework as a proactive method in decreasing students with disabilities' involvement in the SPP. Traumatic SPP experiences are internalized and damaging to the overall well-being of all children, with a disproportionate impact on Black children with disabilities. The Individuals with Disabilities Educational Act of 2005 requires educators to ensure that students with disabilities have equal access to an adequate education in the least restrictive settings (Individuals with Disabilities Educational Act, 2005). Therefore, educators are responsible for using empirical literature, such as this study, to develop academic and behavior models to promote equal access for our most vulnerable students.

\section{REFERENCES}

Aizer, A. and Doyle, J. (2013). What is the long-term impact of incarcerating juveniles? Available at: https://voxeu.org/ article/what-long-term-impact-incarcerating-juveniles

Aleguire, Z., Basallaje, A., Bridges, C., Dudley, K. K., Elgart, A., Paterson, E., Singh, J., Stack, A., Williams, B., and Yakar, I. (2016) Breaking the chains: The school-to-prison pipeline, implicit bias, and racial trauma. https:/ app.box.com/ s/1sduqufd42vqored7arlytr4ofa8v4a7

Andrews, T. (2012). What is social constructionism. Grounded Theory Review, 11(1), 39-46.

Annamma, S. A., Anyon, Y., Joseph, N. M., Farrar, J., Greer, E., Downing, B., and Simmons, J. (2019). Black girls and school discipline: The complexities of being overrepresented and understudied. Urban Education, 54(2), 211242. https://doi.org/10.1177/0042085916646610

Creswell, J. W. (2014) Research Design: Qualitative, Quantitative and Mixed Methods Approaches. Los Angeles, CA: SAGE. DCPS. (n. d.). District of Columbia Public Schools. School profiles. Available at: http://profiles.dcps.dc.gov

DeMatthews, D. E. (2016). The racial discipline gap: Critically examining policy, culture, and leadership in a struggling urban district. Journal of Cases in Educational Leadership, 19(2), 82-96. https://doi.org/10.1177/ 1555458915626758

Denby, R. and Curtis, C. M. (2013). African American Children and Families in Child Welfare: Cultural Adaptation of Services. New York, NY: Columbia University Press.

Fenning, P. and Rose, J. (2007). Overrepresentation of African American students in exclusionary discipline the role of school policy. Urban Education, 42(6), 536-559. https:// doi.org/10.1177/0042085907305039

GFSA. (1990). Gun Free Schools Act of 1990, 18 USC \section 921.

Gibson, P. A., Wilson, R., Haight, W., Kayama, M., and Marshall, J. M. (2014). The role of race in the out-ofschool suspensions of black students: The perspectives of students with suspensions, their parents and educators. Children and Youth Services Review, 47(3), 274-282. https://doi.org/10.1016/j.childyouth.2014.09.020

Hall, M. C. (2019). Critical disability theory. Available at: https://plato.stanford.edu/archives/win2019/entries/ disability-critical/ 
Hewitt, J. (2007). Ethical components of researcher researched relationships in qualitative interviewing. Qualitative Health Research, 17(8), 1149-1159. https://doi.org/10.1177/1049732307308305

Hill, L. A. (2018). Disturbing disparities: Black girls and the school-to-prison pipeline. Fordham Law Review, 87, 5763. https://ir.lawnet.fordham.edu/flro/vol87/iss1/11

Hines-Datiri, D. and Andrews, D. J. C. (2020). The effects of zero tolerance policies on Black girls: Using critical race feminism and figured worlds to examine school discipline. Urban Education, 55(10), 1419-1440. https://doi.org/10.1177\%2F0042085917690204

Hirschfield, P. J. (2008). Preparing for prison?: The criminalization of school discipline in the USA. Theoretical Criminology, 12(1), 79-101. https:/ / doi.org/10.1177/1362480607085795

Hockenberry, S., Sickmund, M., and Sladky, A. (2015) Juvenile Residential Facility Census, 2012: Selected Findings. Washington, DC: US OJJDP

Hogan, A. J. (2019) Social and medical models of disability and mental health: Evolution and renewal. Canadian Medical Association Journal, 191(1), E16-E18. https://doi.org/10.1503/cmaj.181008

Hosking, D. L. (2008). Critical Disability Theory. 4th Biennial Disability Studies Conference. Lancaster University, UK.

Individuals with Disabilities Education Act. (2015). Individuals with Disabilities Education Act of 2015, \$S Subchapter 1-Subchapter 3.

Losen, D. (2018). The need for remedies to the disparate loss of instruction experienced by black students with disabilities. Available at: https://today.law.harvard.edu/wp-content/uploads/2018/04/disabling-punishment-report-.pdf

Losen, D., Hodson, C., Ee, J., and Martinez, T. (2014). Disturbing inequities: Exploring the relationship between racial disparities in special education identification and discipline. Journal of Applied Research on Children, 5(2), 15.

Loughran, T., Mulvey, E. P., Schubert, C. A., Fagan, J., Losoya, S. H., and Piquero, A. R. (2009). Estimating a dose-response relationship between length of stay and future recidivism in serious juvenile offenders. Criminology, 47(3), 699-740. https://doi.org/10.1111/j.1745-9125.2009.00165.x

Macomber, D., Skiba, T., Blackmon, J., Esposito, E., Hart, L., Mambrino, E., Richie, T., and Grigorenko, E. L. (2010). Education in juvenile detention facilities in the state of Connecticut: A glance at the system. Journal of Correctional Education, 61(3), 223-261. https://www.ncbi.nlm.nih.gov/pmc/articles/PMC4569007/

Mallett, C. (2016). The School-to-Prison Pipeline: A Comprehensive Assessment. New York, New York: Springer Publishing Company.

Marchbanks, M. P., Peguero, A. A., Varela, K. S., Blake, J. J., and Eason, J. M. (2018). School strictness and disproportionate minority contact: Investigating racial and ethnic disparities with the "school-to-prison pipeline." Youth Violence and Juvenile Justice, 16(2), 241-259. https:/ / doi.org/10.1177/1541204016680403

McGowan, K. (2014). Experiences of early childhood educators with disabilities: A critical disability theory perspective [Doctoral dissertation, George Mason University]. http://mars.gmu.edu/handle/1920/9168

Miller, C. E. and Meyers, S. A. (2015). Disparities in school discipline practices for students with emotional and learning disabilities and autism. Journal of Education and Human Development, 4(1), 255-267. https://doi.org/ 10.15640/jehd.v4n1a23

Morris, M. (2016). Pushout: The Criminalization of Black Girls in Schools. The New Press.

National Council on Disability. (2015). Breaking the school-to-prison pipeline for students with disabilities. Available at: https://www.ncd.gov/sites/default/files/Documents/NCD_School-to-PrisonReport_508-PDF.pdf

Office of Juvenile Justice Delinquency Prevention. (2017). Jwvenile reentry. Available at: https://www.ojjdp.gov/ $\mathrm{mpg} /$ litreviews/Aftercare.pdf

Pandey, S. and Patnaik, S. (2014). Establishing reliability and validity in qualitative inquiry: A critical examination. Jharkhand Journal of Development and Management Studies, 12(1), 5743-5753. https://www.researchgate.net/profile/ Satyendra_Pandey2

Procknow, G., Rocco, T. S., and Munn, S. L. (2017). (Dis)ableing notions of authentic leadership through the lens of critical disability theory. Advances in Developing Human Resources, 19(4), 362-377. https://doi.org/10.1177/ 1523422317728732

Puzzanchera, C. and Hockenberry, S. (2013). Juvenile court statistics 2010. Available at: https://www.ncjrs.gov/ pdffiles1/ojjdp/grants/244080.pdf

Raffaele-Mendez, L. M. and Knoff, H. M. (2003). Who gets suspended from school and why: A demographic analysis of schools and disciplinary infractions in a large school district. Education and Treatment of Cbildren, 26(1), 30-51. https://www.jstor.org/stable/42900535

Ramey, D. M. (2015) The social structure of criminalized and medicalized school discipline. Sociology of Education, 88(3), 181-201. https://doi.org/10.1177/0038040715587114

Rocco, T. S. (2005). From disability studies to critical race theory: Working towards critical disability theory. Adult Education Research Conference. https: / / newprairiepress.org/ cgi/viewcontent.cgi?article=2685\&context=aerc

Rovner, J. (2016). Racial disparities in youth commitments and arrests. Available at: https:/ /www.sentencingproject.org/ publications/racial-disparities-in-youth-commitments-and-arrests/ 
Scott, M, Underwood, M, and Lamis, D. (2015). Suicide and related-behavior among youth involved in the juvenile justice system. Child and Adolescent Social Work Journal, 32(6) 517-527. https://doi.org/10.1007/s10560-0150390-8

Sheldon-Sherman, J. A. L. (2013). The IDEA of an adequate education for all: Ensuring success for incarcerated youth with disabilities. Journal of Law and Education, 42(2), 227-274.

Snyder, H. N. and Sickmund, M. (2006). Juvenile offenders and victims: 2006 national report. Washington, DC: US D.OJ. OJP OJJDP.

The Sentencing Project. (2017). Black disparities in youth incarceration. Available at: https://www.sentencingproject.org/publications/black-disparities-youth-incarceration/

Townsend, A., Cox, S. M., and Li, L. C. (2010). Qualitative research ethics: Enhancing evidence-based practice in physical therapy, Physical Therapy, 90(4), 615-628. https://doi.org/10.2522/ptj.20080388

US Department of Education Office for Civil Rights. (2021). An overview of exclusionary discipline practices in public schools for the 2017-2018 school year. Available at: https://www2.ed.gov/about/offices/list/ocr/docs/crdcexclusionary-school-discipline.pdf

Vlaev, I. and Dolan, P. (2015). Action change theory: A reinforcement learning perspective on behavior change. Review of General Psychology, 19(1), 69-95. https://doi.org/10.1037/gpr0000029

Yuksel, P. and Yildirim, S. (2015). Theoretical frameworks, methods, and procedures for conducting phenomenological studies in educational settings. Turkish on Journal of Qualitative Inquiry, 6(1), 1-20. https://doi.org/10.17569/tojqi.59813

Zhang, D., Barrett, D. E., Katsiyannis, A., and Yoon, M. (2011). Juvenile offenders with and without disabilities: Risks and patterns of recidivism. Learning and Individual Differences, 2(1), 12-18. https://doi.org/10.1016/ j.lindif.2010.09.006 